\title{
Perancangan Iklan Gim Mobile Activia Sebagai Media Periklanan Android
}

\author{
Mochammad Amirul Hakim \\ Mahasiswa Program Studi Disain Komunikasi Visual \\ Fakultas Seni Rupa ISI Yogyakarta \\ mochammad.amha@gmail.com
}

\begin{abstract}
Age of information require people to think fast. Slowly, both electronic ads and print ads are lost their attraction. So that new media for advertise need to renew somehow.

Game isn't kind of luxurious toys these days. Most people can play it freely or buy with their smartphones, everywhere at anytime. They can play, share, update, even play in a group on different state with internet technology features on mobile phone.

This design is try to combine advertise with mobile game as media. Using the addictive of the game, people can get more features to win the game with buy then scanning $Q R$ code within product package. The object of this design is Activia. Activia is healthy yogurt product. The goal is this design is using mobile game for advertising to sell product more effective and efficiently.
\end{abstract}

Keywords: Activia, Gim, Food, Mobile, Yogurt.

Relevance to Visual Communication Design Practice: Perancangan ini merupakan perancangan iklan yang menggunakan media baru yaitu gim mobile. Diharapkan, perancangan iklan dengan media baru ini mampu menjadi sarana periklanan yang lebih efektif dan ekonomis dalam dunia desain komunikasi visual

\section{LATAR BELAKANG}

Memasuki era globalisasi teknologi berkembang demikian cepat dan dinamis. Kecepatan informasi dan komunikasi menjadi tolak ukur kemajuan suatu negara. Demikian canggihnya teknologi informasi sehingga memudahkan masyarakat untuk berbagi. Segala kebutuhan hidup tanpa terkecuali komunikasi visual dituntut untuk mengikuti perubahan agar tidak ketinggalan zaman. Kemajuan teknologi komunikasi telah memungkinkan terjadinya Globalisasi informasi. Oleh karena itu, masyarakat dituntut untuk siap menghadapi banjirnya informasi disegala bidang khususnya iklan.
Managing Direktor Fortune PR Indira Abidin mengatakan, dalam riset yang dikutipnya dari Zenith Optimedia Juni 2013 disebutkan, pertumbuhan iklan di media internet global sepanjang 2012-2015 akan melaju paling signifikan.

Dengan kontribusi lebih dari US\$ 46 juta, media internet menjadi penyumbang terbesar dalam pertumbuhan belanja iklan global, melesat di atas televisi (US\$25,2 juta), koran (US\$ 6,4 juta), media luar-ruang (US\$ 5,5 juta), majalah (US\$ 3 juta), dan radio (US\$ 2,6 juta).

Melihat fungsi media elektronik yang begitu luas, maka secara otomatis akan 
memberikan kesadaran hendaknya kita dapat memanfaatkannya secara tepat. Ini berarti tantangan baru untuk desainer komunikasi visual. Peran iklan hingga saat ini masih signifikan dalam mempengaruhi keputusan konsumen membeli sebuah produk. Bisnis iklan di dunia akan terus meningkat, yang dipimpin oleh iklan media internet.

Dalam riset tersebut, Indonesia juga menunjukkan potensi periklanan yang signifikan. Kontribusi pertumbuhan belanja iklan Indonesia pada tahun 2012 hingga 2015 diprediksi menduduki peringkat empat dunia.Amerika Serikat duduk di peringkat puncak dengan pertumbuhan belanja iklan sebesar US\$21,1 juta, disusul Tiongkok (US\$ 13 juta), Argentina (US\$ 4,8 juta), Indonesia (US\$ 4,1 juta), dan Rusia (US\$ 3,28 juta).

Di pasar smartphone Indonesia, Head of Corporate Communications Group Telkomsel Adita Irawati menyebutkan, hingga triwulan I tahun 2013 ini tercatat dari sekitar 120 juta pelanggan Telkomsel saja, 5,7 juta di antaranya merupakan pengguna Blackberry, 3 juta pengguna Android dan 310 ribu pengguna iPhone. Sedangkan pertumbuhan Android pada tahun 2013 diprediksi akan terus meningkat berkisar 2030\% dibandingkan tahun 2012 lalu. Sementara itu pertumbuhan BlackBerry diperkirakan berada di kisaran 5\% saja. (detik.com)

Data di atas menunjukan betapa besar kebutuhan iklan telah berkembang saat ini. Namun perlu disadari bahwa semakin banyak jumlah iklan, maka semakin sulit juga suatu produk dapat berdiri bersaing dengan produk lainnya. Pelaku periklanan terutama desainer komunikasi visual dituntut untuk dapat menemukan solusi untuk beiklan dengan memanfaatkan teknologi yang ada, tidak memakan banyak biaya, serta jauh lebih penting adalah tepat sasaran.

Data yang didapat dari berita yang dipublis oleh okezone.com mereka telah menerima laporan yang mengungkap lebih dari setengah pengguna internet mobile umumnya berusia muda, yakni di bawah 24 tahun. Laporan juga mengungkap sebesar 71 persen pengguna internet di Indonesia adalah pria dan 29 persen wanita.Laporan yang sama juga menyinggung sifat-sifat konsumtif, yakni tipe konten yang diminati oleh konsumen di Indonesia serupa dengan pengguna internet di negara lainnya di Asia Tenggara. Pengguna di Indonesia gemar mengunduh game dan aplikasi sebesar $70 \%$.

Masih berdasarkan data diatas, dalam mencari media yang baik untuk beriklan tepat sasaran adalah dengan media yang bersifat personal, informatif dan menghibur. 
Smartphone menjadi pilihan utama untuk menyampaikan informasi saat ini. Jumlah pengguna smartphone pada tahun 2011 di Indonesia mencapai 11 juta orang dan diprediksi meningkat mencapai 18 juta pada tahun 2015 seperti dilansir dari jaringnews.com. Smartphone menjadi solusi beriklan karena menawarkan banyak fitur dan kemudahan dalam mengakses informasi.

Menurut laporan yang dikeluarkan perusahaan analisis Flurry, pengguna smartphone menghabiskan 2 jam 38 menit, dengan 32 persen dari waktu itu digunakan untuk bermain gim. Demikian dilansir dari Pocket-lint.

Gim merupakan salah satu layanan hiburan yang ditawarkan smartphone. Dengan media interaktif digital ini diharapkan para masyarakat dapat menerima informasi-informasi positif tentang produk serta membangun public awareness.

Activia adalah merek dagang yoghurt milik Danone. Activia diklasifikasikan sebagai makanan fungsional, yang dirancang untuk meningkatkan kesehatan pencernaan. ProdukActivia mengandung Bifidobacterium animalis DN 173 010, kerabat Bifidobacterium, sebuah probiotik yang dipasarkan oleh Danone di bawah nama dagang Bifidus Regularis, Bifidus Actiregularis, Bifidus
Digestivum dan Bifidobacterium lactis. Praktik pemasaran perusahaan telah menghasilkan beberapa litigasi dimana perusahaan telah menyelesaikan masalah tanpa disertai pengakuan tanggung jawab.

Produk Activia dijual di lebih dari 40 negara di seluruh dunia. Kebanyakan produk yoghurt Activia mengandung buah. Setiap porsi Activia berisi lebih dari 1 triliun dari basil tersebut, bekerja untuk membantu mencegah atau menyembuhkan konstipasi, masalah yang mempengaruhi sekitar 17\% dari populasi, menurut sebuah studi dari ACNielsen. Walaupun produk Activia telah terkenal di seluruh dunia, namun belum banyak yang tahu manfaat dan kegunaan produk Yogurt ini. Dalam acara Indonesia Degistive Disease Week 2012 yang diadakan oleh Perkumpulan Gastroenterologi Indonesia (PGI) pada tanggal sembilan Oktober lalu, sebagian besar pesertanya adalah dokter spesialis yang rutin mengkonsumsi yogurt activia. Acara ini memberi gambaran tentang produk activia yang aman untuk dikonsumsi secara rutin bahkan dapat memberi banyak manfaat pada konsumennya. Oleh karena itu diperlukan media iklan yang dapat menyampaikan informasi seputar manfaat produk serta kegunaan yang tepat sasaran, menarik, dan 
ekonomis dengan memanfaatkan teknologi saat ini.

\section{RUMUSAN MASALAH}

Bagaimana merancang sebuah game mobile dalam format digital berbasis microprocessor yang dapat berinteraksi langsung dengan konsumen dan dapat mengingatkan konsumen tentang produk activia?

\section{BATASAN PERANCANGAN}

Merancang sebuah game mobile berbasis microprocessor yang dapat memberi tampilan animasi dan interaksi sentuhan khususnya untuk Android (Smartphone) dengan konten informatif serta menarik yang dapat membangun public awareness di mata konsumen.

\section{MANFAAT PERANCANGAN}

Dalam perancangan game mobile Activia ini diharapkan dapat membawa manfaat di antara:

\section{Bagi Mahasiswa Disain Komunikasi Visual}

Game Mobile ini diharapkan bisa menjadi salah satu referensi alternatif media pendukung untuk kampanye-kampanye produk yang tidak menggunakan biaya besar tetapi tetap menarik dan mudah dalam proses penyebarluasannya.

\section{Bagi Institusi Disain Komunikasi Visual}

Menjadi salah satu referensi desain game mobile.

\section{Bagi Masyarakat}

Melalui perancangan ini diharapkan dapat menyampaikan manfaat produk pada target audience, merubah pandangan masyarakat terhadap iklan dan meningkatkan public awareness terhadap produk.

\section{SISTEMATIKA PERANCANGAN}

Skematika perancangan gim mobile Activia adalah sebagai berikut:

Perancangan Game Design Document, Perancangan Aset Gim, Perancangan Karakter Gim, Implementasi Karakter Gim, Koding Gim, Penambahan Sound Effect dan UploadGim.

\section{PEMBAHASAN DAN VISUALISASI}

\section{Tahap perancangan}

Gim adalah media iklan yang belum banyak dipakai, namun sudah ada sejak akhir tahun 90an. Media ini tidak begitu banyak dibuat karena biaya pembuatannnya dulu terlampau mahal. Kini seiring berkembangnya teknologi dan hadirnya smartphone memungkinkan gim mobile dibuat dengan mudah dan murah.

Gim mobile sebagai media periklanan memiliki kelebihan mudah didistibusikan melalui media online. Jutaan masyarakat telah 
memiliki smartphone yang mampu mengoperasikan gim.

Media baru memiliki potensi untuk lebih diterima target audience daripada media yang sudah ada.

Di samping itu, gim bersifat entertain atau menghibur, dimana pesan lebih mengena di benak target audience.

\section{Konsep Gim}

Food Diary adalah gim bertema Platformer yang mana pemain di haruskan untuk melompat dan berlari sepanjang level sambil menghindari rintangan-rintangan yang ada. Pemain akan dihadapakan pada jajaran makanan yang telah disusus secara acak untuk diraih serta susunan rintangan untuk dihindari. Pemain dinyatakan memenangkan permainan apabila berhasil mendapatkan buah dan makanan yang dibutuhkan. Jenis buah dan makanan dalam setiap level tidak selalu sama. Sebaliknya, pemain dinyatakan kalah apabila tidak berhasil mendapatkan buah dan makanan yang ditargetkan.

Yang unik dari gim ini adalah sistem Real-Time. Tiap level hanya bisa diakses 1 kali waktu dalam satu hari, artinya apa bila pemain tidak memainkan gim pada waktu yang telah ditentukan, pemain tidak akan dapat memainkan level tersebut lagi tanpa bantuan Item tertentu.

\begin{tabular}{|l|l|}
\hline CPU & $\begin{array}{l}\text { Qualcomm } \\
\text { Snapdragon } \\
\text { MSM8225 1.2 GHz, } \\
\text { Andreno 203 GPU }\end{array}$ \\
\hline Operating System & $\begin{array}{l}\text { Android v3.1 Ice } \\
\text { Cream Sandwich }\end{array}$ \\
\hline Memory Internal & 2 Gigabyte \\
\hline Camera & 2 Megapixels \\
\hline
\end{tabular}

Tabel 1 Minimum System Requirements (Smartphone). Sumber: Dokumen Penulis

\section{Cerita}

Via adalah seorang peri gizi. Tugasnya menyeleksi makanan setiap hari yang sehat untuk di konsumsi. Dalam menjalankan tugasnya, Via harus terbang berkeliling negeri makanan untuk mendapatkan makanan yang sehat untuk dikonsumsi. Sayangnya, tidak semua makanan yang ada di negeri makanan selalu menyehatkan. Via akan jatuh dan mati apabila terlalu banyak membawa makanan yang berlemak dan tidak sehat.

\section{Setting}

Dalam Gim ini, seluruh aktifitas Via berada di negeri makanan. Ada rumah kue, pohon es krim, dan bahkan sungai susu. Via terbang melintas di atas bangunan dan hutan yang keseluruhannya terbuat dari makanan.

\section{Game Play}

Via harus mendapatkan sekaligus menghindari makanan yang ditargetkan. Dalam setiap sub-level, terdapat 2 jenis makanan yang harus di dapatkan dan harus 
dihindari. Misal, dalam pada level 1, Via harus mendapatkan 3 buah apel dan 5 buah telur, tetapi Via tidak boleh mengenai roti cake, dan es krim.

Via dikatakan menang apabila berhasil mendapatkan makanan yang diperlukan. Sebaliknya, Via dinyatakan gagal apabila menabrak makanan larangan atau objek lain dalam jumlah tertentu.

\section{Kalender dan level}

Mirip dengan Map dalam gim pada umumnya. Kalender ini berfungsi untuk melihat dan mencatat jumlah level dan sublevel pemain yang telah diselesaikan dan yang terlewati. Kalender ini dibuat agar pemain disiplin dan konsisten memainkan gim.

\section{Real-Time}

Gim Food Diary harus terintegrasi dengan fitur jam pada smartphone. Hal ini agar pemain dapat mengakses sub-level sesuai dengan waktu yang telah disediakan. Terdapat 3 waktu dalam 1 hari untuk memainkan permainan, yaitu pada pukul 7.00, pukul 12.00 dan pukul 19.00. Jika pemain lupa atau tidak mampu melewati sublevel pada waktu tersebut, maka pemain tidak dapat memainkan sub-level itu lagi tanpa bantuan Item “Time Jumper”.

\section{Nyawa dan periode permainan}

Dalam satu periode permainan, (pukul 07.00, pukul 12.00 dan pukul 19.00) pemain akan diberikan 5 nyawa atau 5 kali kesempatan menyelesaikan sub-level. Jika nyawa ini habis, pemain tidak dapat memainkan sub-level tersebut lagi. Tanpa bantuan Item "Leaf of Life"

\section{Special Item}

Adalah Item-item khusus dalam dunia Food Diary yang berguna untuk melangsungkan permainan. Special Item ini bukan item yang dapat diperoleh pemain dari dalam gim. Pemain harus men-scan QR code (Quick Respon Code) yang ada dalam setiap kemasan Activia berlabel khusus. Terdapat 2 Item Khusus dalam gim ini yaitu:

\section{Time Jumper}

Adalah item yang berfungsi untuk mengakses kembali sub-level yang terlewati. Pemain dapat memainkan kembali sub-level yang gagal dimainkan atau terlewati dengan bantuan item ini dengan persediaan nyawa yang tersisa.

\section{Leaf of Life}

Adalah item yang dapat mengembalikan nyawa atau kesempatan main kembali utuh. 


\section{Karakter}

Via adalah peri gizi yang berjuang mengumpulkan makan bergizi dan sehat setiap hari.

\section{QR code pada Produk}

1 kemasan Activia yang berlabel khusus memiliki QR code di dalamnya. Pemain dapat men-scan QR code tersebut untuk mendapatkan beberapa Coin guna ditukarkan dengan Special item. Setiap kemasan Activia memuat 100 keping Coin dalam QR code nya.

\section{Makanan}

Makanan dalam gim ini adalah penentu kemenangan sekaligus kekalahan Via. Terdapat makanan yang harus di dapatkan, maupun dihindari tergantung dari target tiap sub-level. Masing-masing sub-level memuat target yang berbeda-beda.

\section{Coin}

Adalah alat tukar yang sah dalam gim ini. Coin berfungsi untuk ditukarkan dengan special item.

\section{Model Karakter}

Via adalah peri gizi perempuan. Dia terlihat feminim dan bentuk tubuhnya ramping. Dia memiliki sepasang sayap mungil untuk terbang. Via mengenakan dress dan scraft serupa dengan warna produk Activia.

\section{User Interface}

Berdasarkan seting dan tema gim, user interface yang baik adalah yang bersifat ceria, penuh warna tapi didominasi warna hijau karena identik dengan warna produk dan warna makanan sehat seperti sayur-sayuran.

\section{Environment dan Asset}

Serba makanan adalah ide dasar dari gim ini. Sangat penting menampilkan berbagai jenis environment dalam bentuk yang segar, terlihat lezat dan penuh warna yang memanjakan mata.

\section{Background Model}

Negeri makanan adalah negeri yang tercipta dari berbagai jenis makanan.

\section{Share}

Pemain juga dapat berbagi rekor ke jejaring sosial Facebook untuk saling unjuk gigi jumlah level yang telah di laluinya.

\section{Konsep Kendali}

Gim berjalan di atas platform touchscreen, sehingga player harus memainkan game dengan menekan layar untuk menggerakan karakter dalam gim saat mengindari rintangan ataupun mengambil coin.

\section{Font dan Tipografi}

Jenis huruf yang cocok untuk gim bertema makanan adalah dekoratif namun tidak terlalu 
rumit agar tingkat keterbacaan masih terjaga saat di aplikasikan dalam device yang kecil.

\section{Musik dan Sound Asset}

Agar pemain lebih dapat merasakan permainan, soundeffect sangat diperlukan. Soundeffect berfungsi tidak hanya sebagai peramai, namun juga informasi bahwa karakter pemain sedang berinteraksi dengan object di sekitarnya.

\section{Background Music}

Senada dengan gaya visual, musik dalam gim ini secara keseluruhan bernada ceria dan menyenangkan, tanpa ada efek ketegangan. Musik yang cocok adalah instrumental dengan bit sedang. Berikut adalah layar yang memerlukan musik yang berbeda-beda agar menuntun perasaan pemain dalam memainkan gim.

\section{VISUALISASI}

\section{Sketsa dan pengembangan ide}

Gim Food Diary adalah gim yang bertujuan untuk memasarkan produk dan mengenalkan manfaatnya pada konsumen. Gim ini diharapkan mampu menjadi penjembatan antara konsumen dan produk. Semua tampilan visual merupakan penggabungan antara gaya karakter kartun yang cenderung kekanak-kanakan agar dapat diterima oleh semua kalangan. Warna yang ada dalam gim didominasi oleh warna hijau produk. 

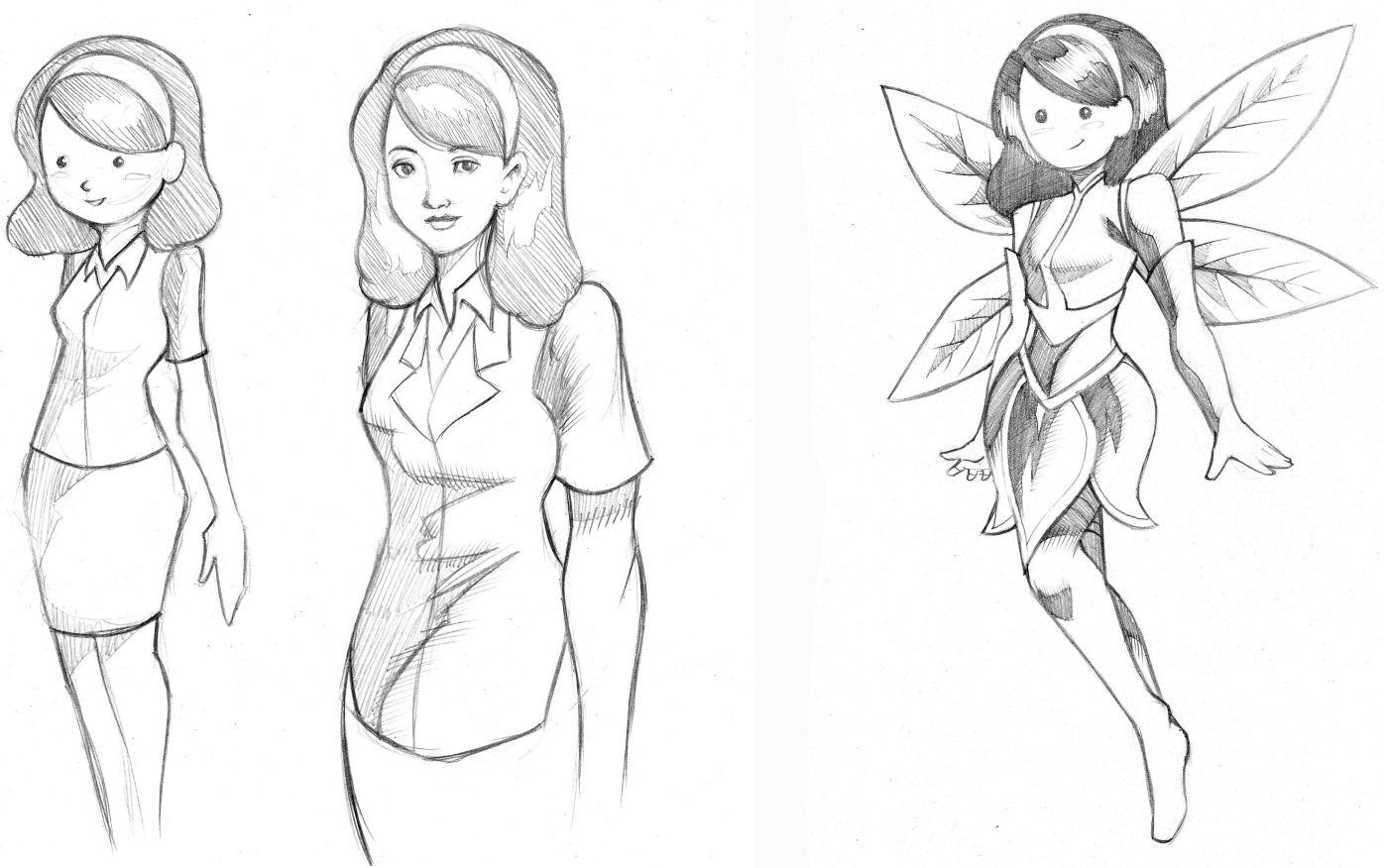

Gambar 1 Sketsa Karakter Via dalam gim Food Diary Sumber : Amirul Hakim 2014
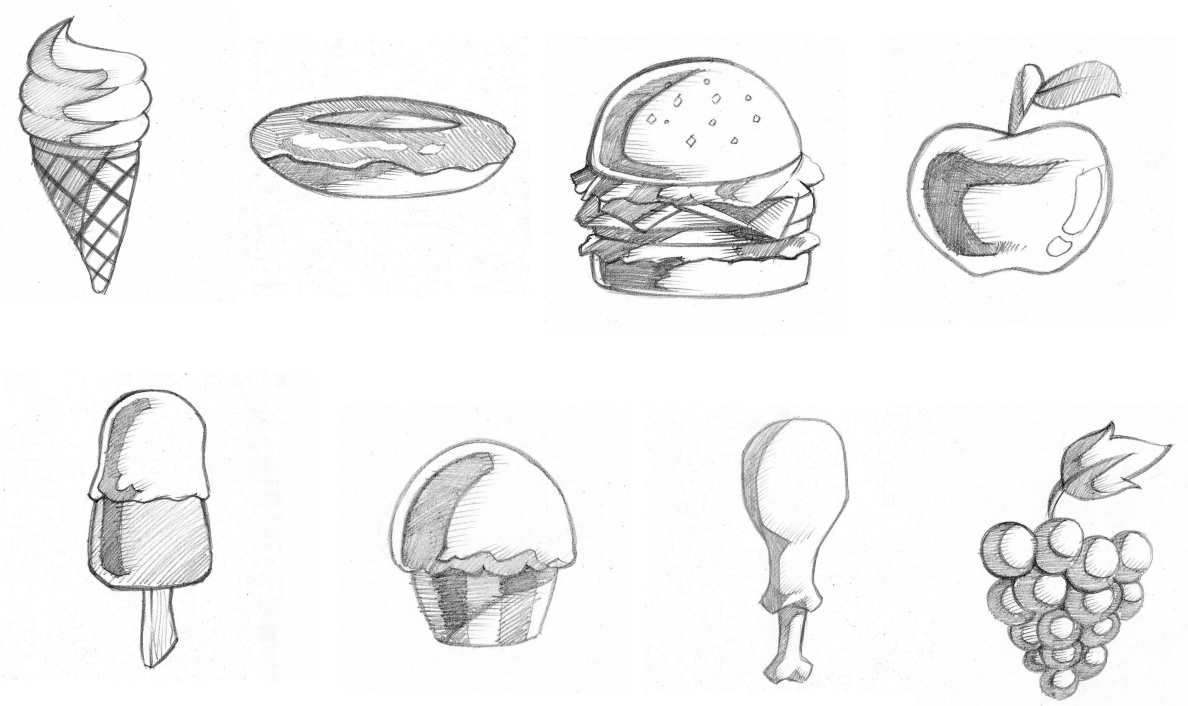

Gambar 2 Sketsa Buah-buahan Dalam gim Food Diary (Sumber : Amirul Hakim 2014) 


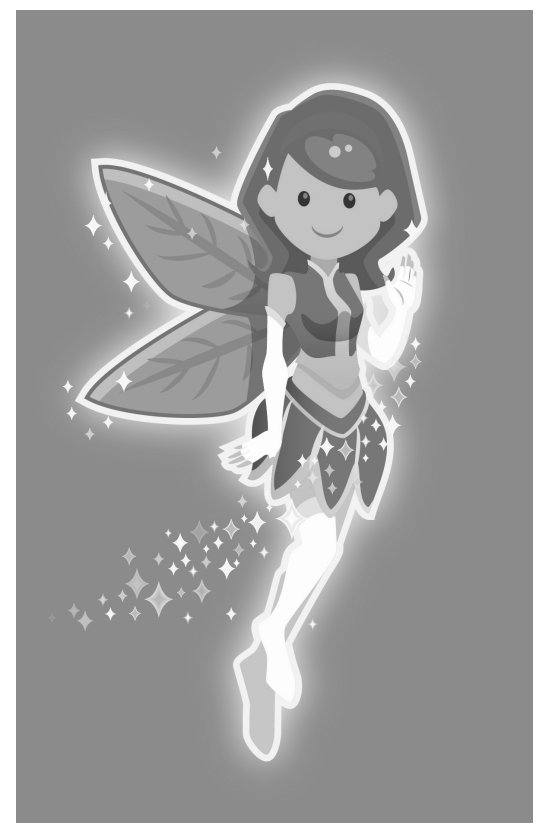

Gambar 3 Karakter Via Dalam gim Food Diary (Sumber: Amirul Hakim, 2014)
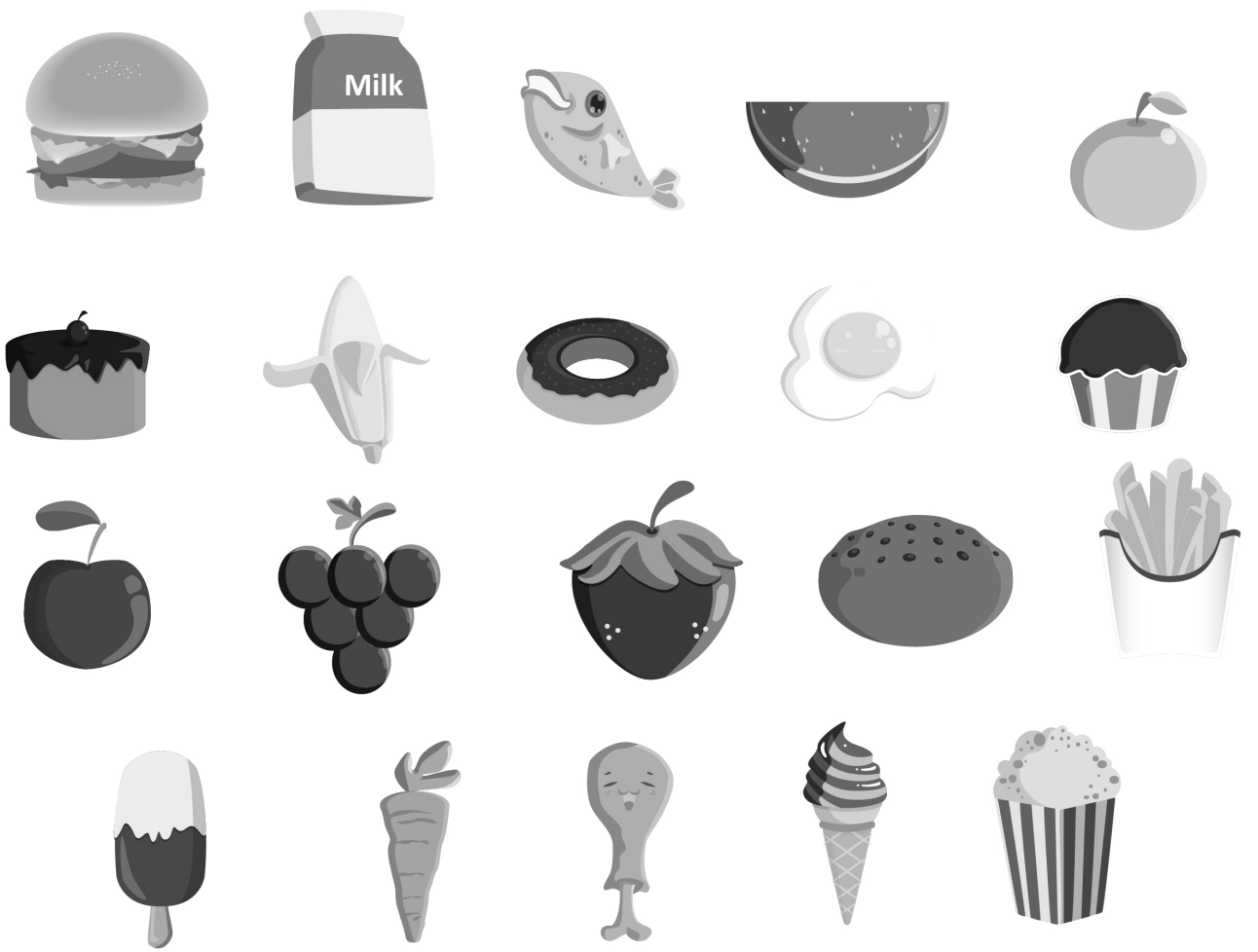

Gambar 4 Buah-buahan Dalam gim Food Diary (Sumber: Amirul Hakim, 2014) 


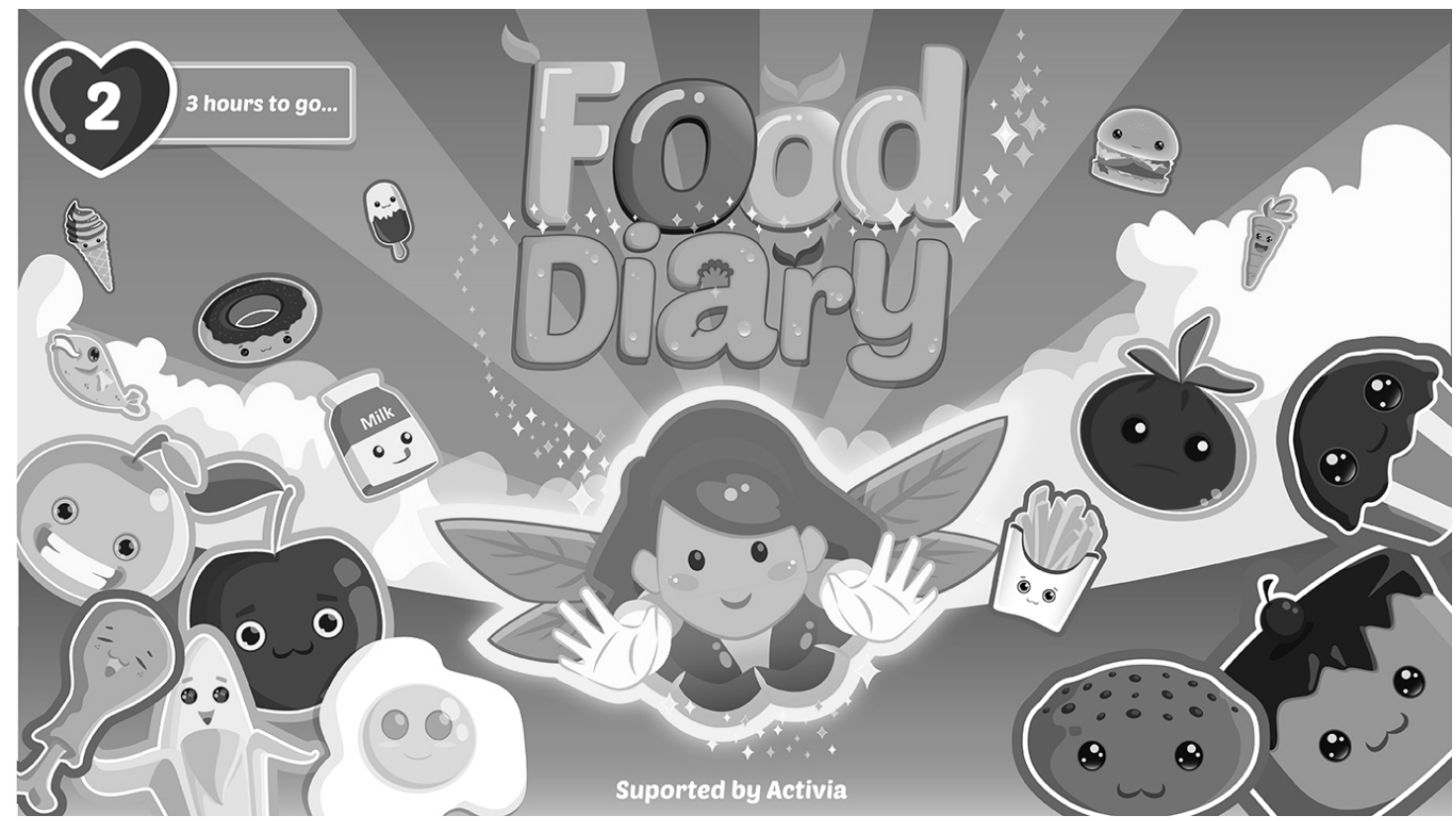

Gambar 5 Opening Screen Dalam gim Food Diary (Sumber : Amirul Hakim 2014)

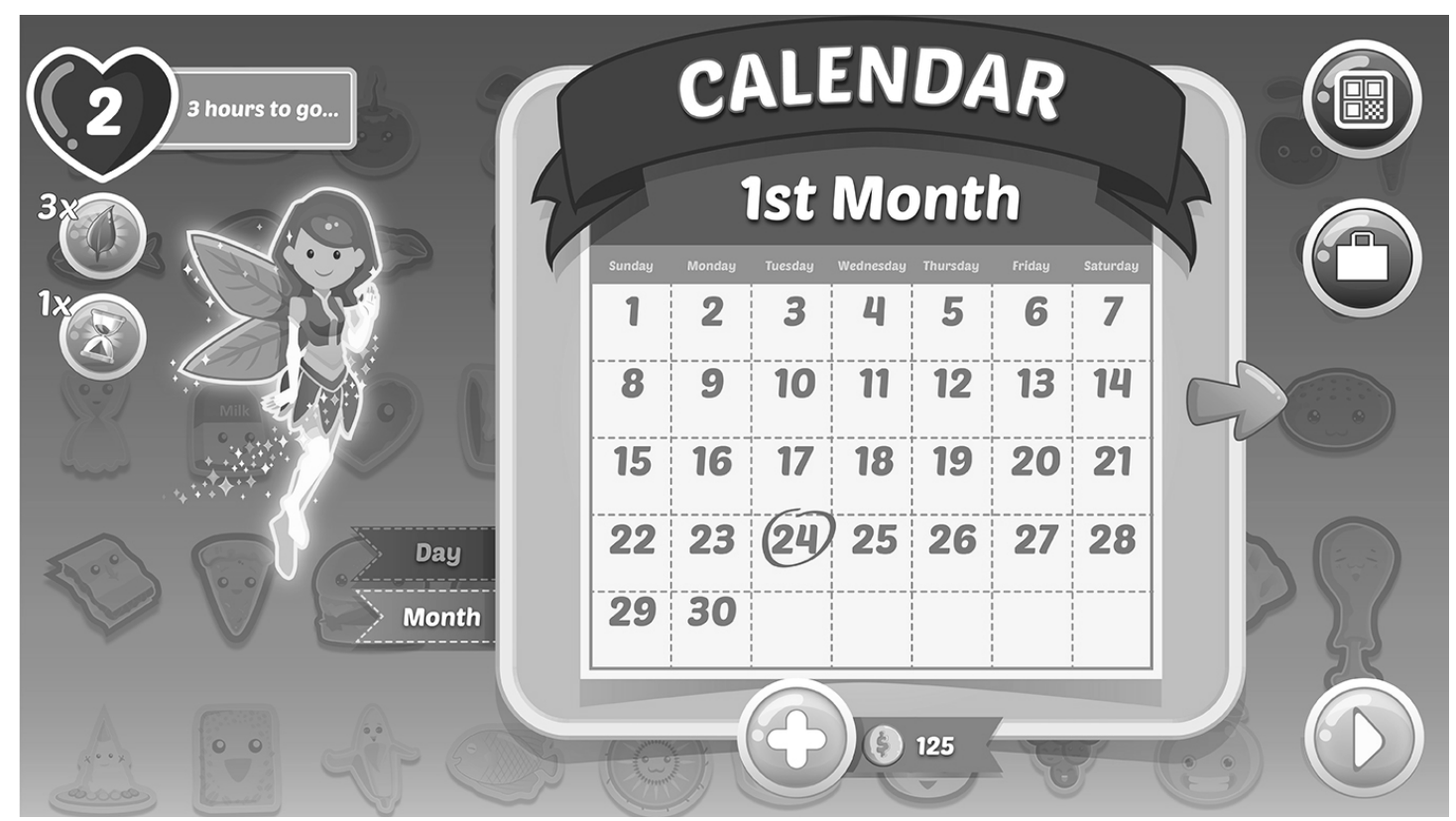

Gambar 6 Laman Menu Level Dalam gim Food Diary (Sumber : Amirul Hakim 2014) 


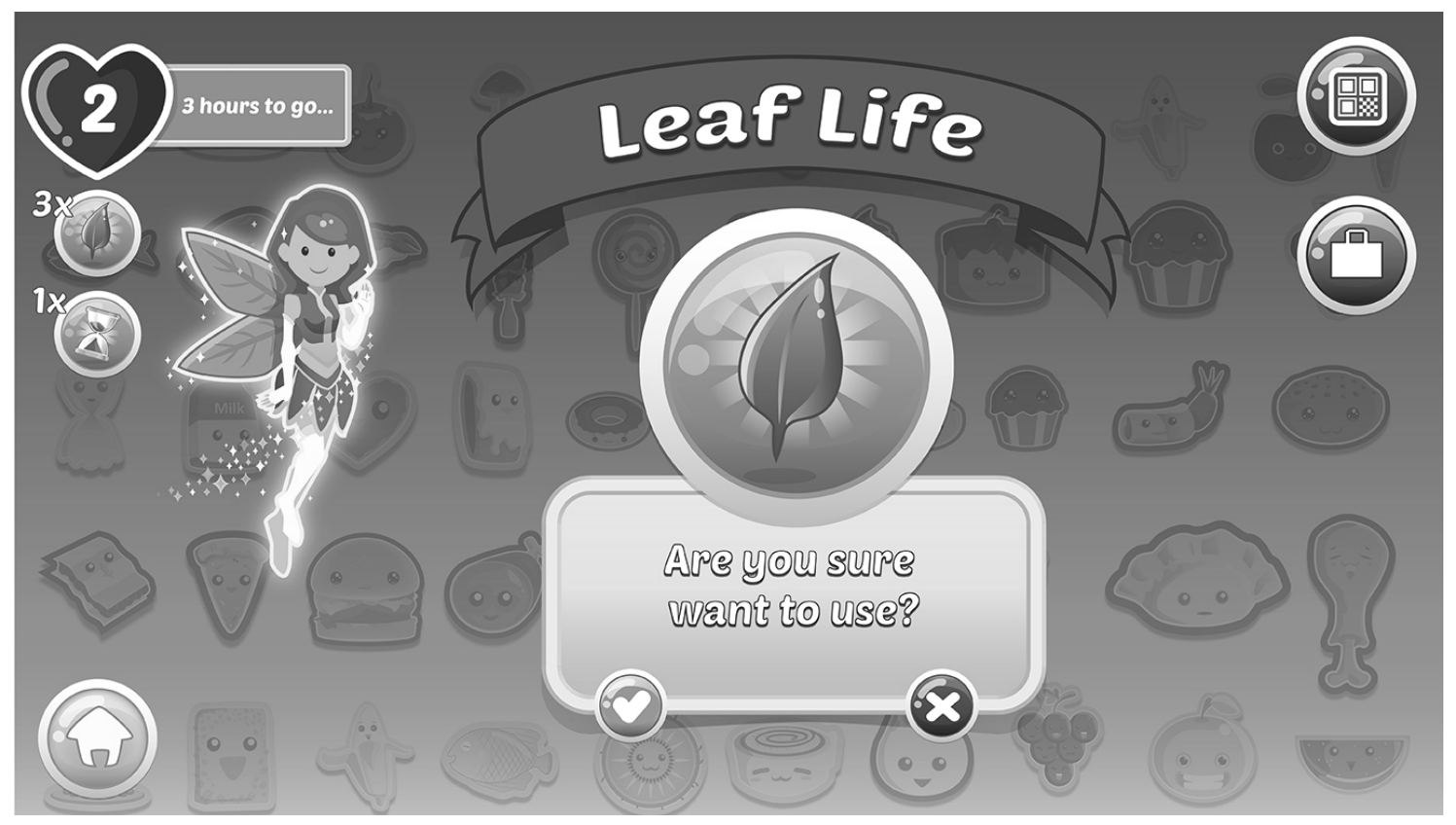

Gambar 7 Laman Use Item Dalam gim Food Diary (Sumber : Amirul Hakim 2014)

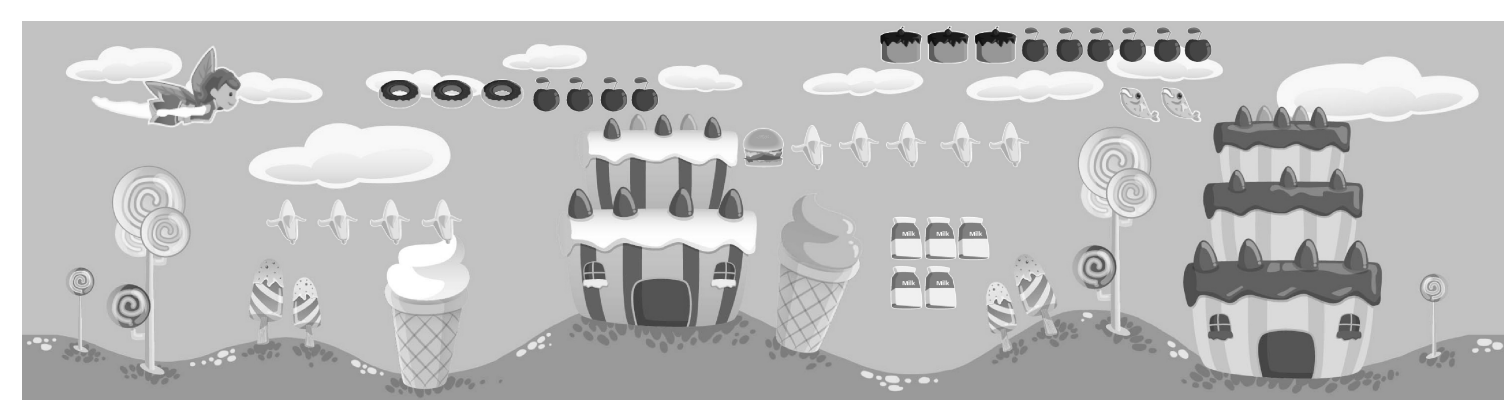

Gambar 8 Tampilan gim Dalam gim Food Diary

(Sumber : Amirul Hakim 2014) 


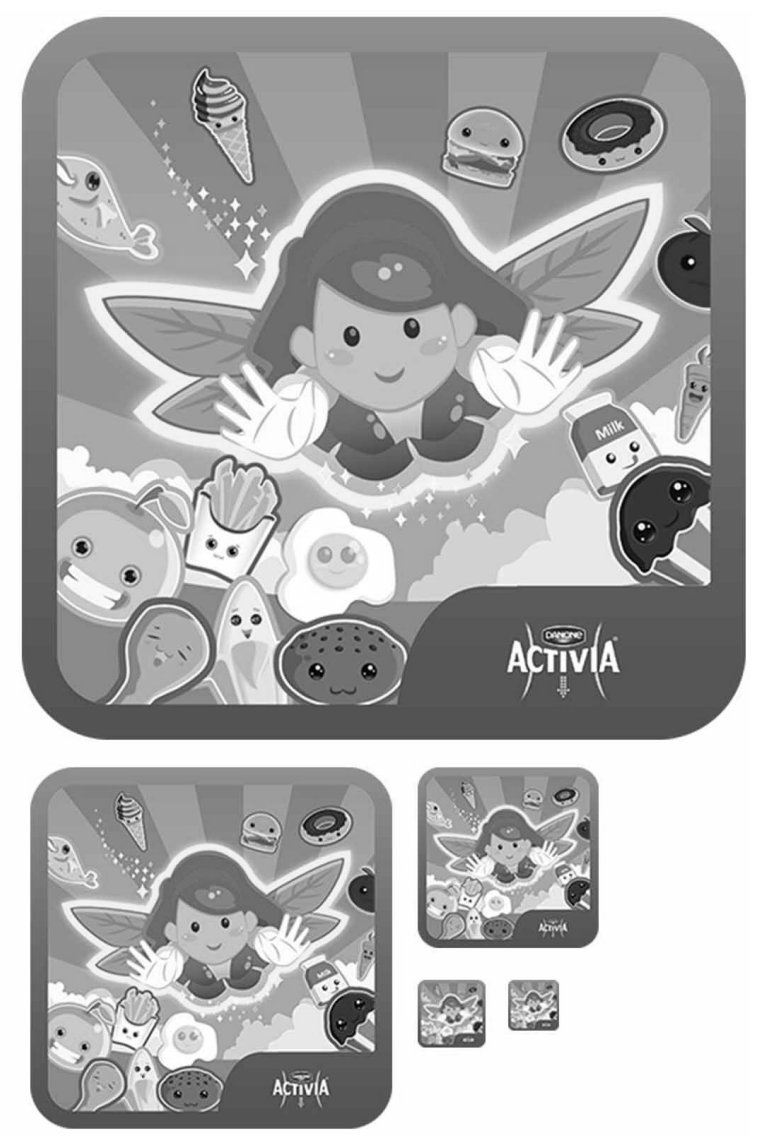

Gambar 9 Icon gim Food Diary (Sumber : Amirul Hakim 2014)

\section{KESIMPULAN}

Perancangan gim mobile bertema advertising adalah hal baru. Layaknya hal baru, tingkat keberhasilannya tergantung pada seberapa baik hasil akhir dari gim ini. Penerimaan target audience akan baik apabila gim ini dirancang dan diselesaikan dengan baik.

Kesulitan dalam perancangan gim ini adalah minimnya referensi tentang gim bertema yang sama. Namun demikian, bukan tidak mungkin di selesaikan karena teknologi gim zaman sekarang telah maju. Dengan mencontoh dan memadukan referensi gim lain yang telah ada, hasil terbaik sangat mungkin dicapai. Beberapa referensi yang diperlukan telah dilampirkan dalam tugas akhir ini.

Kesulitan lain yang mungkin hadir adalah sistem pembaca kode QR. Secara teknis telah banyak aplikasi yang disertai pembaca kode QR atau QR code reader dan dapat bekerja dengan baik. Namun demikian, belum banyak yang memadukannya dalam gim. 


\section{DAFTAR PUSTAKA}

[1] Bates Bob. (2004). Game Design, $2^{\text {nd }}$ (ed.). United State of America: Thomson Course Technology PTR.

[2] Danang Sunyoto. (2012). Dasar-dasar Manajemen Pemasaran. Yogyakarta: CABS.

[3] Feil John and Scattergood. (2005). Beginning Game Level Design. United State of America: Thomson Course Technology PTR.

[4] Jason Darby. 2008. Game Creation for Teens. United State of America: Thomson Course Technology PTR.

[5] Pardew Les. 2004. Game Arst For Teens. United State of America: Thomson Course Technology PTR.

[6] Rogers Scott. 2010. Level Up!. United Kingdom: A John Wiley \& Sons, Ltd., Publication.

[7] Rouse Richard. 2005. Game Design Theory, $2^{\text {nd }}$ (ed.). Texas: Wordware Publishing, Inc.

[8] Suyanto M. 2003. Strategi Periklanan pada E-Commerce Perusahaan Top Dunia.

[9] Wenats Eka, Kurniawaty Yusuf, Leonita K. Syarief, Putut Widjanarko, Rini Sudarmanti, Suraya, Tri Wahyuti, Wahyutama, Ratno Suprapto. Integrated Marketing Communications: Komunikasi Pemasaran di Indonesia. 2012. Jakarta: PT.Gramedia Pustaka. 